\title{
Analisis Konten Kesehatan Mental Dalam Karya Musik Kendrick Lamar
}

\author{
Muhammad Fandy Erlambang ${ }^{1}$, Ikhsan Fuady ${ }^{2}$, S. Kunto Adi Wibowo ${ }^{3}$ \\ ${ }^{123}$ Universitas Padjadjaran, Sumedang, Indonesia \\ Email: muhammad19271@mail.unpad.ac.id
}

\begin{abstract}
During the 2000s and 2010s, mental health problems of Generation Z youth increased, but efforts to seek help decreased. However, rap music can be one of the several interventions that can help them. In this content analysis research, the authors apply a quantitative analysis method to the lyrics contained in the music of Kendrick Lamar, one of the most popular rap musicians during the 2010s. The analysis was conducted on a sample of 58 Kendrick Lamar songs to find the number of mental health references in his musical works from 2011 to 2017. The sampling technique used was purposive sampling. Data analysis techniques include frequency analysis, Cochran-Armitage test for trends in linear proportions, and cross-tabulations test using SPSS. Based on analysis results, it was found that 31 of the 58 songs in the sample contained mental health references. Mental health references in Kendrick Lamar's music increased from 2011 to 2012, but decreased from 2012 to 2017. The mental health references found were also related to contributing factors such as environmental conditions, spiritual beliefs, and love life. The writing of this research is expected to contribute to the realm of content analysis of rap music and popular music as a whole.
\end{abstract}

Keywords: Mental health reference, Kendrick Lamar, rap music

\begin{abstract}
Abstrak: Selama dekade 2000-an serta 2010-an, masalah kesehatan mental pada kaum pemuda generasi $\mathrm{Z}$ mengalami peningkatan, namun terdapat penurunan pada upaya mereka untuk memperoleh bantuan. Walaupun begitu, musik rap dapat menjadi salah satu dari sejumlah intervensi yang dapat membantu mereka. Dalam penelitian analisis konten ini, penulis menerapkan metode analisis kuantitatif terhadap lirik lagu yang terdapat pada karya musik Kendrick Lamar, salah satu musisi rap yang paling popular selama dekade 2010-an. Analisis dilakukan terhadap sampel sebanyak 58 lagu Kendrick Lamar untuk menemukan jumlah referensi kesehatan mental dalam karya musiknya pada tahun 2011 hingga 2017. Teknik sampling yang digunakan adalah purposive sampling. Teknik analisis data menggunakan analisis frekuensi, uji Cochran-Armitage test for trends in linear proportions, dan uji cross-tabulations menggunakan perangkat lunak SPSS. Berdasarkan hasil analisis, ditemukan bahwa sebanyak 31 dari 58 lagu yang ada dalam sampel mengandung referensi kesehatan mental. Referensi kesehatan mental dalam karya musik Kendrick Lamar mengalami peningkatan pada tahun 2011 hingga 2012, namun menurun pada tahun 2012 hingga 2017. Referensi kesehatan mental yang ditemukan juga berkaitan dengan faktor-faktor kontributor seperti kondisi lingkungan sekitar, kepercayaan rohani, serta kehidupan percintaan. Penulisan penelitian ini diharapkan dapat berkontribusi terhadap ranah analisis konten musik rap dan musik populer secara keseluruhan.
\end{abstract}

Kata Kunci: Referensi kesehatan mental, Kendrick Lamar, musik rap

Article info:

Received: 14 Juni 2021

Reviewed: 23 Juni 2021

Accepted: 29 Juni 2021

\section{PENDAHULUAN}

Masalah-masalah yang menyangkut topik seperti kesehatan mental telah menjadi sering terlihat dalam masyarakat selama abad ke-21, terutama pada dekade 2000-an serta 2010-an
(Kresovich dkk., 2021). Seperti yang disampaikan oleh Twenge dkk. (2019) dalam Kresovich dkk. (2021), sepanjang tahun 2008 hingga 2017, telah terjadi sebuah peningkatan pada resiko-resiko bunuh diri dan juga tekanan 
psikologis di antara penduduk berusia 18 hingga 25 tahun yang tinggal di negara Amerika Serikat. Selain itu, juga terdapat data penelitian oleh Mojtabai (2016) dalam Kresovich dkk. (2021) yang menunjukkan bahwa sepanjang tahun 2005 hingga 2014, gejala-gejala depresi besar yang diderita oleh mereka yang berusia 12 hingga 20 tahun telah menjadi semakin lazim. Walaupun masalah-masalah kesehatan mental terlihat semakin meningkat, jumlah orang-orang yang berusaha untuk menyelesaikan masalah tersebut masih tergolong rendah (Wynaden dkk., 2014).

Dalam penelitian-penelitian yang sebelumnya telah dilakukan oleh Giamos dkk. (2017), ditemukan bahwa dari sejumlah remaja yang mengidap kegelisahan dan juga depresi, hanya sebagian kecil dari mereka yang mendapat diagnosa atau mencari pengobatan untuk menyembuhkan penyakit-penyakit mental tersebut. Di Amerika Serikat sendiri, sedikitnya jumlah pemuda yang mencari bantuan terhadap masalah-masalah kesehatan mentalnya tersebut menempatkan mereka pada posisi sebagai salah satu kelompok remaja yang paling tidak mungkin untuk memanfaatkan layanan-layanan kesehatan mental (Giamos dkk., 2017). Oleh karena itu, jumlah pemuda berusia 10 hingga 24 tahun yang melakukan tindakan bunuh diri di negara Amerika Serikat mengalami peningkatan yang sangat signifikan pada rentang waktu 10 tahun antara tahun 2007 hingga 2017 (Gunnell dkk., 2018).

Berdasarkan apa yang disampaikan oleh Kresovich dkk. (2021), salah satu intervensi yang sangat menjanjikan bagi pemuda-pemuda yang memiliki resiko seperti masalah kesehatan mental adalah musik rap. Bagi para pemuda, khususnya pemuda Afrika-Amerika, musik rap merupakan salah satu hal yang membawa pengaruh yang cukup besar bagi perkembangan sosial serta identitas pribadi mereka. Selain itu, telah tercatat pada tahun 2018 bahwa musik rap memiliki demografis khalayak audiens yang termuda di Amerika Serikat dan juga dipertimbangkan sebagai genre musik favorit di antara kalangan pemuda Amerika Serikat yang berusia 16 hingga 24 tahun (Kresovich dkk., 2021). Seperti apa yang telah disampaikan sebelumnya, maka tujuan yang ingin dicapai penulis pada penelitian ini adalah untuk mengetahui referensi-referensi kesehatan mental yang terdapat dalam karya musik Kendrick Lamar yang merupakan salah satu musisi rap yang paling populer selama dekade 2010-an (Sule \& Inkster, 2015).
Dipaparkan bahwa, terdapat peningkatan yang signifikan pada masalah-masalah seputar kesehatan mental yang menimpa para pemuda. Lebih spesifiknya, mereka tergolong dalam suatu kelompok generasi yang dinamakan generasi Z (Gunnell dkk., 2018). Generasi Z adalah sebuah golongan yang diisi oleh pemuda yang lahir dalam jangka waktu pertengahan dekade 1990-an hingga awal dekade 2000-an. Yang membedakan generasi $\mathrm{Z}$ dengan generasigenerasi sebelumnya adalah bagaimana kehidupan mereka semua terikat erat dengan teknologi, terutama teknologi digital yang dapat menjelaskan mengenai peningkatan masalah kesehatan mental yang tidak hanya menimpa pemuda-pemuda di Amerika Serikat saja, namun juga di negara-negara lain. Pada umumnya, faktor-faktor resiko kesehatan mental yang rendah dapat berupa trauma serta penganiayaan, namun pada masa kini, faktor-faktor resiko tersebut juga dapat berupa tingginya penggunaan media sosial seperti Facebook dan Snapchat pada kalangan pemuda yang dapat menyebabkan sejumlah masalah, seperti tekanan untuk senantiasa aktif dalam perbincangan dan interaksi, berkurangnya interaksi dan komunikasi tatap muka, munculnya rasa haus akan validasi sosial, serta berkurangnya kualitas tidur (Gunnell dkk., 2018).

Masalah kesehatan mental bukanlah sesuatu yang hanya menimpa generasi $\mathrm{Z}$ saja. Pada generasi-generasi sebelumnya, seperti yang ditunjukkan dari penelitian yang dilakukan oleh Soet dan Sevig (2006) terhadap mahasiswamahasiswa pada dekade 1990-an hingga 2000-an bahwa beberapa dari masalah-masalah paling signifikan yang mereka hadapi adalah depresi, kegelisahan, serta bunuh diri.

Pada masa kini, masalah-masalah seputar kesehatan mental tetap menjadi masalah utama yang dihadapi oleh para pemuda di penjuru dunia, seperti pada negara Selandia Baru, dimana sebanyak seperempat pemuda yang berada di negara tersebut terpengaruhi oleh depresi serta kegelisahan (Goodyear-Smith dkk., 2017). Oleh karena itu, bunuh diri menjadi penyebab kematian utama pada pemuda Selandia baru yang berusia 10 hingga 24 tahun. Dalam negara lain seperti Australia pula, terdapat sebanyak lebih dari 50 persen mahasiswa dari tiga universitas yang mengalami kesukaran psikologis yang mengindikasikan adanya penyakit mental (Wynaden dkk., 2014). Selain itu, Adlaf dkk. (2005) dalam Giamos dkk. (2017) menyatakan bahwa sebanyak hampir 
sepertiga dari pemuda yang menjadi mahasiswa di negara Kanada melaporkan bahwa mereka pernah mengalami kesukaran psikologis yang cukup tinggi. Data yang disampaikan sebelumnya menunjukkan bahwa masalah kesehatan mental merupakan suatu hal yang seringkali tampak pada kalangan pemuda dan juga mereka yang menduduki bangku pendidikan tinggi, namun walaupun begitu, hanya segelintir dari mereka yang mencari atau mendapat bantuan yang mereka butuhkan untuk menyelesaikan masalah yang mereka miliki.

Seperti yang disampaikan oleh Kresovich dkk. (2021), pemuda-pemuda yang berada di negara Amerika Serikat termasuk ke dalam golongan yang paling tidak mungkin untuk memanfaatkan layanan kesehatan mental. Hal yang sama pun juga dapat ditemukan di negaranegara lain. Di Selandia Baru, sebagian besar dari masyarakat pemuda tidak melakukan akses terhadap perawatan utama untuk menyelesaikan masalah kesehatan mental mereka walaupun tersedianya pengobatan-pengobatan yang efektif di negara tersebut. Selain itu, Stallman (2008) dalam Wynaden dkk. (2014) menyatakan bahwa pemuda-pemuda yang menjadi mahasiswa di Australia tetap menunda atau tidak sama sekali mencari bantuan untuk menyelesaikan masalah mereka, walaupun tingkatan kesukaran psikologis yang mereka miliki diasosiasikan dengan berapa hari mereka tidak mampu untuk mencapai komitmen belajar serta pekerjaan. Di Kanada, khususnya Alberta, ditemukan bahwa terdapat sedikit terapi jangka panjang bagi para mahasiswa, walaupun hampir separuh dari institusi yang ada di kota tersebut memiliki pusat layanan konseling.

Berbeda dengan tren-tren musik ataupun busana yang sebelumnya telah ada, musik rap bukanlah sesuatu yang lahir dari pemikiranpemikiran industri musik ataupun kepentingan bisnis yang lainnya, melainkan berawal dari daerah-daerah lingkungan dalam kota sebagai cerminan yang sejati akan aspirasi, kekhawatiran dan jua harapan-harapan yang dimiliki oleh para pemuda, terutama pemuda Afrika-Amerika yang tinggal di Amerika Serikat. Musik rap merupakan sebuah bentuk musik populer yang berasal dari New York City di Amerika Serikat pada akhir dekade 1970-an. Musik rap itu sendiri berisi seorang vokalis yang melakukan rapping terhadap musik latar belakang yang ritmis. Selain itu, musik rap juga terdiri dari komponenkomponen musikal serta lirik yang membedakan bentuk musik tersebut dengan bentuk musik yang lainnya, seperti flow, gaya musikal, gaya ritmis, serta konten semantik (Lena, 2006). Pada awal perkembangannya, musik rap memiliki nilai-nilai serta karakteristik yang melekat dengan lingkungan yang bersifat menindas, namun sangat inovatif. Pada masa kini, musik rap telah berpindah ke bentangan dimana musik tersebut menjadi salah satu bagian dari budaya populer, namun tetap memiliki nilai dan juga karakteristik yang telah ada sejak awal munculnya musik rap.

Musik rap telah menjadi sebuah suara yang sangat besar bagi para pemuda urban. Romero (1997) dalam Armstrong \& Ricard (2016) memaparkan bahwa musik rap membawa pengaruh yang sifatnya internasional terhadap berbagai bidang, seperti seni, tari, busana, bahasa, serta wicara. Walaupun pada umumnya lirik-lirik yang terkandung dalam musik rap memiliki unsur-unsur seperti misogini, penyalahgunaan obat-obatan, serta perilakuperilaku kekerasan, musik rap dijelaskan oleh Travis (2013) dalam Armstrong \& Ricard (2016) sebagai bentuk musik yang kaya akan pesanpesan mengenai pengalaman hidup, strategi menghadapi tantangan hidup, dan juga perspektif mengenai cara memprioritaskan strategi-strategi tersebut. Sebagai salah satu jalan untuk menyelesaikan masalah kesehatan mental, terapi rap telah dibuktikan oleh dokterdokter terapi dan juga pekerja sosial sebagai cara yang efektif dalam mempromosikan hasil kesehatan mental yang positif.

Salah satu musisi yang bergerak dalam genre musik rap adalah seseorang yang memiliki nama panggung Kendrick Lamar yang berasal dari Amerika Serikat. Sebagai seseorang yang telah menduduki posisi sebagai salah satu musisi rap yang paling populer selama dekade 2010 -an, Kendrick Lamar sendiri melebarluaskan genre musik rap secara keseluruhan dengan mendorong musiknya sendiri ke berbagai bentuk dan arah yang baru (Faraji, 2016 dalam Rocha, 2017). Salah satu aspek yang paling menonjol dari karya musik Kendrick Lamar adalah penggunaan naratif yang memanfaatkan pesanpesan alegori serta perumpamaan yang tersebar sepanjang bagian-bagian naratif yang pendek dan juga diperpanjang (Faraji, 2016 dalam Rocha, 2017). Selain itu, Sule dan Inkster (2015) menyatakan bahwa karya musik yang dibawakan Kendrick Lamar mengandung elemen-elemen naratif yang berkaitan erat dengan topik-topik kesehatan mental seperti kecanduan, depresi, serta ketahanan. 
Dalam penelitian ini, penulis melakukan analisis terhadap lirik-lirik lagu yang terkandung dalam karya musik Kendrick Lamar untuk menemukan referensi terhadap topik kesehatan mental. Oleh karena itu, penulis merumuskan sebanyak satu research question serta 2 hipotesis yang berbunyi sebagai berikut:

RQ1: Seberapa banyak referensi kesehatan mental yang terdapat dalam karya musik Kendrick Lamar semenjak tahun 2011 hingga 2017?

H0: Referensi kesehatan mental dalam karya musik Kendrick Lamar mengalami peningkatan semenjak tahun 2011 hingga 2017

H1: Referensi kesehatan mental dalam karya musik Kendrick Lamar mengalami penurunan semenjak tahun 2011 hingga 2017

\section{METODE}

Pada penelitian ini, penulis menggunakan perangkat lunak SPSS untuk melakukan penelitian yang bersifat komparatif yang membandingkan banyaknya referensi kesehatan mental dalam karya musik Kendrick Lamar pada tahun 2011, 2012, 2015, serta 2017. Penulis juga menggunakan uji analisis Cochran-Armitage test for linear trends in proportions untuk menemukan jumlah referensi kesehatan mental dari tahun 2011 hingga 2017. Kemudian penulis juga menggunakan uji Cross-tabulations untuk menemukan kebersamaan kemunculan referensi kesehatan mental serta faktor-faktor kontributor dalam satu lagu.

Dalam penelitian ini, penulis memilih populasi berupa keseluruhan diskografi Kendrick Lamar yang terdiri atas 7 album rekaman serta 15 single. Penentuan populasi tersebut dilakukan dengan mengakses laman profil Kendrick Lamar pada layanan musik Spotify. Kemudian, penulis melakukan sampling dengan menggunakan teknik non-probabilitas berupa purposive sampling (Riffe dkk., 2006) yang menghasilkan sampel berupa 58 lagu yang berasal dari 4 album rekaman Kendrick Lamar. Keempat album rekaman tersebut dirilis pada rentang waktu 2011 hingga 2017.

Untuk menguji reliabilitas antar-coder, maka penulis menetapkan koefisien reliabilitas Krippendorff yang sebesar 0,8 keatas (Hughes, 2021). Dengan begitu, dapat diharapkan terdapatnya reliabilitas antar-coder. Dalam proses uji reliabilitas, penulis mengunggah data yang dikemas dalam file dengan format CSV kepada alat komputasi daring yang bernama Reliability Calculator for Ordinal, Interval, and Ratio data untuk mengetahui reliabilitas antar- coder. Setelah dilakukannya analisis, ditemukan bahwa koefisien reliabilitas Krippendorff untuk semua variabel lebih besar dari 0,8 .

Pada lembaran coding sheet, para coder mengisi data dari setiap lagu yang dianalisis, kemudian, para coder akan membaca lirik-lirik dari semua lagu tersebut untuk menemukan referensi mental health conditions yang ada. Lirik dari lagu-lagu tersebut disediakan melalui situs web genius.com yang sebelumnya telah diredaksi untuk memotong bagian-bagian lirik yang sifatnya non-musikal, seperti intro dan outro. Setelah mengidentifikasi mental health conditions yang sesuai dengan konteks di mana Kendrick Lamar mereferensikan kondisi kesehatan mentalnya sendiri, para coder kemudian mengisi data pada kolom-kolom yang sesuai. Jika terdapat referensi terhadap mental health conditions dalam lagu yang dianalisis, maka coder akan menentukan contributing factor dari referensi tersebut yang kemudian juga akan diisi datanya pada kolom-kolom contributing factor yang sesuai.

\section{HASIL DAN PEMBAHASAN}

\section{Hasil}

Berdasarkan hasil analisis yang telah dilakukan, peneliti kemudian menyusun hasil tersebut sedemikian rupa ke dalam bentuk Tabel 1 yang menunjukkan total seberapa banyak lagu yang menunjukkan referensi kesehatan mental terhadap 4 topik yang berbeda, seperti anxiety, depression, mental health condition metaphor, serta suicide atau suicide ideation. Terdapat sebanyak $13,8 \%$ dari total 58 lagu yang mereferensikan anxiety, dan sebanyak 12,1\% dari total 58 lagu yang menunjukkan referensi terhadap depression. Selain itu, referensi terhadap mental health condition metaphor berjumlah $22,4 \%$ dari total 58 lagu, serta sebanyak 5,2\% dari total 58 lagu mereferensikan suicide atau suicidal ideation.

Data yang terlihat pada Tabel 2 menunjukkan seberapa banyak referensi terhadap kesehatan mental dan faktor-faktor kontributor terhadap referensi tersebut. Dari data tersebut, Faktor environment yang memiliki 13 referensi bersamaan, faith yang memiliki 11 referensi bersamaan, serta love life yang memiliki 8 referensi bersamaan menduduki 3 posisi referensi bersamaan yang paling banyak. Di sisi lain, faktor kontributor friend memiliki referensi bersamaan dengan kesehatan mental yang paling sedikit dengan 2 kebersamaan. 
Tabel 1. Uji Analisis Deskriptif

\begin{tabular}{llllllll}
\hline & Referensi Kesehatan Mental & $\begin{array}{l}\text { Total } \\
(\mathrm{n}=58)\end{array}$ & $\begin{array}{l}2011 \\
(\mathrm{n}=16)\end{array}$ & $\begin{array}{l}2012 \\
(\mathrm{n}=12)\end{array}$ & $\begin{array}{l}2015 \\
(\mathrm{n}=16)\end{array}$ & $\begin{array}{l}2017 \\
(\mathrm{n}=14)\end{array}$ & P Value \\
\hline 1 & Anxiety & 8 & 4 & 2 & 0 & 2 & 0,198 \\
2 & Depression & 7 & 1 & 4 & 2 & 0 & 0,401 \\
3 & Mental Health Condition Metaphor & 13 & 5 & 4 & 2 & 2 & 0,146 \\
4 & Suicide & 3 & 0 & 1 & 2 & 0 & 0,774 \\
\hline
\end{tabular}

Tabel 2. Jumlah Referensi Bersamaan terhadap Kesehatan Mental serta Faktor Kontributor

\begin{tabular}{lllllll}
\hline No & Faktor Kontributor & Anxiety & Depression & Metaphor & Suicide & Total \\
\hline 1 & Authority & 3 & 0 & 1 & 1 & 5 \\
2 & Environment & 4 & 3 & 4 & 2 & 13 \\
3 & Faith & 4 & 1 & 6 & 0 & 11 \\
4 & Family & 2 & 1 & 3 & 1 & 7 \\
5 & Financial & 1 & 1 & 2 & 2 & 6 \\
6 & Foe & 2 & 0 & 1 & 0 & 3 \\
7 & Friend & 1 & 0 & 1 & 0 & 2 \\
8 & Job & 0 & 0 & 3 & 0 & 3 \\
9 & Love Life & 2 & 2 & 3 & 1 & 8 \\
10 & Professional & 1 & 1 & 1 & 0 & 3 \\
11 & Universal Conditions & 1 & 0 & 1 & 1 & 3 \\
\hline
\end{tabular}

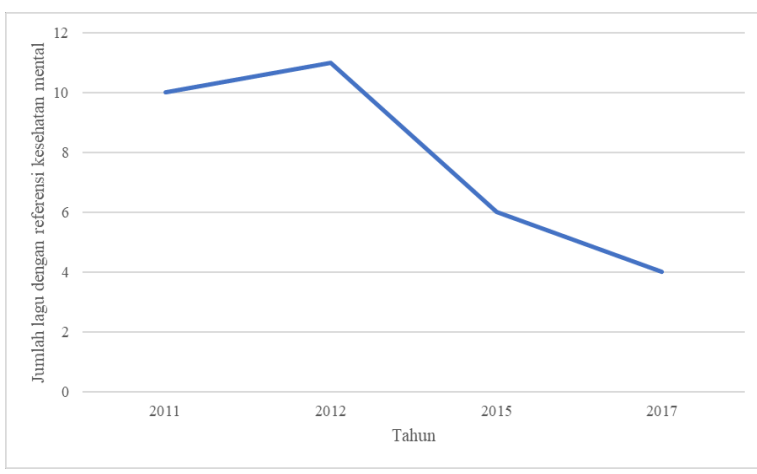

Bagan 1. Jumlah keseluruhan lagu Kendrick Lamar yang mengandung referensi kesehatan mental

\section{Pembahasan}

Dalam penelitian ini, peneliti mengambil sampel sebanyak 58 lagu yang tersebar dalam 4 album rekaman Kendrick Lamar. Album rekaman pertama adalah Section. 80 yang dirilis pada tahun 2011. Album tersebut berisi sebanyak 15 lagu, dan semua lagu tersebut dipilih oleh peneliti sebagai sampel penelitian.

Album rekaman kedua Kendrick Lamar adalah good kid, m.A.A.d city yang dirilis pada tahun 2012, yang dimana peneliti memilih sebanyak 12 dari 14 keseluruhan lagu yang ada dalam album tersebut sebagai sampel. Dua lagu yang tidak diambil sebagai sampel dari album tersebut berjudul Bitch, Don't Kill My Vibe - Remix serta Bitch, Don't Kill My Vibe - International Remix
/ Explicit Version, dengan alasan bahwa lirik kedua lagu tersebut secara garis besar sama dengan lagu Bitch, Don't Kill My Vibe pada album good kid, m.A.A.d city, hanya saja dengan penambahan penampilan dari musisi lain, sehingga tidak sesuai dengan coding guide penelitian.

Selanjutnya, album rekaman Kendrick Lamar yang ketiga adalah To Pimp A Butterfly yang dirilis pada tahun 2015 dan berisi 16 lagu yang dimana peneliti memilih semua lagu tersebut sebagai sampel. Kemudian, album rekaman Kendrick Lamar yang keempat adalah $D A M N$. Yang dirilis pada tahun 2017 dan berisi sebanyak 14 lagu yang semuanya dipilih oleh peneliti sebagai sampel penelitian.

Analisis yang dilakukan oleh peneliti menunjukkan bahwa dari sebanyak 58 lagu karya Kendrick Lamar yang dirilis dalam rentang waktu tahun 2011 hingga 2017, secara keseluruhan terdapat sebanyak 31 lagu yang mengandung referensi terhadap kesehatan mental. Dari semua referensi kesehatan mental yang ditemukan, referensi terhadap mental health condition metaphor adalah yang memiliki kemunculan paling banyak, yaitu pada 13 lagu; sedangkan, referensi terhadap suicide atau suicidal ideation adalah yang paling sedikit muncul, yaitu pada 3 lagu. Tingginya referensi terhadap mental health condition metaphor 
meunjukkan bahwa Kendrick Lamar sebagai seorang musisi memiliki ketergantungan kepada referensi tersebut untuk menyampaikan pesan kesehatan mental secara konotatif agar dapat lebih diterima oleh para audiensnya (Kresovich dkk., 2021).

Data yang ditampilkan pada Bagan 1 menunjukkan bahwa banyaknya lagu yang mengandung referensi kesehatan mental mengalami peningkatan dari tahun 2011 yang berjumlah 10 lagu hingga 2012 yang berjumlah 11 lagu, namun angka tersebut mengalami penurunan pada tahun 2012 hingga 2017, dimana jumlah lagu yang mereferensikan kesehatan mental berjumlah 4 lagu pada 2017.

Data yang ditampilkan pada Tabel 2 menunjukkan bahwa faktor-faktor kontributor yang paling banyak bersamaan muncul dengan referensi kesehatan mental meliputi environment, faith, serta love life. Prevalensi tiga faktor kontributor tersebut menandakan bahwa dalam karya musiknya, Kendrick Lamar mengaitkan referensi kesehatan mental dengan faktor-faktor seperti kondisi lingkungan pemukiman, kepercayaan terhadap agama dan tuhan, serta kehidupan cinta dengan pasangan romantis.

\section{KESIMPULAN}

Berdasarkan hasil analisis yang telah dilakukan pada penelitian ini, peneliti dapat mengambil kesimpulan bahwa dari keseluruhan 58 lagu yang ada dalam sampel penelitian, terdapat sebanyak 31 lagu yang mengandung referensi terhadap kesehatan mental. Peneliti juga mengambil kesimpulan bahwa pada sepanjang tahun 2011 hingga 2017, jumlah lagu Kendrick Lamar yang mereferensikan kesehatan mental mengalami penurunan yang signifikan, dari sebanyak 11 lagu pada 2012 menjadi 4 lagu pada 2017. Selain itu, lagu-lagu yang mengandung referensi kesehatan mental tersebut memiliki faktor kontributor yang saling berkaitan dengan referensi kesehatan mental. Tiga dari faktor kontributor yang paling banyak bersamaan muncul dengan referensi kesehatan mental meliputi kondisi lingkungan, kepercayaan rohani, serta kehidupan romansa.

\section{DAFTAR PUSTAKA}

Armstrong, S. N., \& Ricard, R. J. (2016). Integrating Rap Music Into Counseling With Adolescents in a Disciplinary Alternative Education Program. Journal of Creativity in Mental Health, 11(3-4), 423-435. https://doi.org/10.1080/15401383.2016.1 214656

Giamos, D., Lee, A. Y. S., Suleiman, A., Stuart, H., \& Chen, S.-P. (2017). Understanding Campus Culture and Student Coping Strategies for Mental Health Issues in Five Canadian Colleges and Universities. Canadian Journal of Higher Education, 47(3), 136-151. https://doi.org/10.47678/cjhe.v47i3.1879 57

Goodyear-Smith, F., Martel, R., Darragh, M., Warren, J., Thabrew, H., \& Clark, T. C. (2017). Screening for risky behaviour and mental health in young people: The YouthCHAT programme. Public Health Reviews, $38(1), \quad 20$. https://doi.org/10.1186/s40985-0170068-1

Gunnell, D., Kidger, J., \& Elvidge, H. (2018). Adolescent mental health in crisis. BMJ, k2608. https://doi.org/10.1136/bmj.k2608 Kresovich, A., Reffner Collins, M. K., Riffe, D., \& Carpentier, F. R. D. (2021). A Content Analysis of Mental Health Discourse in Populer Rap Music. JAMA Pediatrics, 175(3), 286. https://doi.org/10.1001/jamapediatrics.20 20.5155

Lena, J. C. (2006). Social Context and Musical Content of Rap Music, 1979-1995. Social Forces, 85(1), 479-495. https://doi.org/10.1353/sof.2006.0131

Powell, C. T. (1991). Rap Music: An Education with a Beat from the Street. The Journal of Negro Education, 60(3), 245. https://doi.org/10.2307/2295480

Soet, J., \& Sevig, T. (2006). Mental Health Issues Facing a Diverse Sample of College Students: Results from the College Student Mental Health Survey. NASPA Journal, 43(3), 22.

Travis, R. (2013). Rap Music and the Empowerment of Today's Youth: Evidence in Everyday Music Listening, Music Therapy, and Commercial Rap Music. Child and Adolescent Social Work Journal, 30(2), 139-167. https://doi.org/10.1007/s10560-0120285-x

Wynaden, D., McAllister, M., Tohotoa, J., Al Omari, O., Heslop, K., Duggan, R., Murray, S., Happell, B., \& Byrne, L. (2014). The Silence of Mental Health Issues Within University Environments: 
A Quantitative Study. Archives of Psychiatric Nursing, 28(5), 339-344. https://doi.org/10.1016/j.apnu.2014.08.00 3

Sule, A., \& Inkster, B. (2015). Kendrick Lamar, street poet of mental health. The Lancet Psychiatry, 2(6), 496-497. https://doi.org/10.1016/S22150366(15)00216-3

Riffe, D., Lacy, S., \& Fico, F. (2006). Analyzing Media Messages $(0$ ed.). Routledge. https://doi.org/10.4324/9781410613424
Hughes, J. (2021). krippendorffsalpha: An R Package for Measuring Agreement Using Krippendorff's Alpha Coefficient. ArXiv:2103.12170 [Stat]. http://arxiv.org/abs/2103.12170

Rocha, D. (2017). Kendrick Lamar and Hip-Hop as a Medium for Social Change. Student Publications.

https://cupola.gettysburg.edu/student_sch olarship/545 